\title{
Men, ApPearance, and Cosmetic Surgery: The Role of Self-ESTEEM AND COMFORT WITH THE BODY
}

\author{
ROSEMARY RICCIARDELLI \\ Kimberley Clow
}

\begin{abstract}
This paper situates male perceptions of the body within Bourdieu's theories of human practice. Recent research (Bordo 1999; Featherstone 1991; Giddens 1991; Gill, Henwood, and McLean 2005) has suggested that perceptions of the body are important to men's sense of confidence and that men see the body as a vehicle for personal improvement. To build on this research, an online survey investigated Canadian men's perspectives on their appearance and their attitudes toward cosmetic surgery. A two-component approach to self-esteem was used, where self-confidence (the positive aspect) and self-deprecation (the negative aspect) were seen as independent but related concepts that underlie one's feelings of self-worth. Self-deprecation, self-confidence, and comfort with one's body uniquely predicted different aspects of men's experiences, including attitudes about body shape, perceptions of others, pressures to lose weight, and perspectives regarding cosmetic surgery. For example, participants who were more comfortable with their bodies and lower in self-deprecation were happier with their current body shape and features, whereas participants who were less comfortable with their bodies and lower in confidence put more pressure on themselves to lose weight. In addition, lower confidence significantly predicted willingness to undergo cosmetic surgery.
\end{abstract}

Key Words: masculinity; body; self-esteem; self-deprecation; self-confidence

Résumé. Cet article situe la perception masculine du corps au sein des théories de Bourdieu sur la pratique humaine. De récentes recherches (Bordo 1999; Featherstone 1991; Giddens 1991; Gill, Henwood, et McLean 2005) portent à croire que les perceptions du corps sont importantes pour la confiance en soi chez l'homme, et que celui-ci voit le corps comme un véhicule de son implication personnelle. Un sondage en ligne portant sur les points de vue de l'homme canadien sur l'apparence et l'attitude à l'égard de la chirurgie esthétique a été mené pour renforcer cette recherche. On a utilisé une approche à deux volets à l'égard de l'estime de soi où la confiance en soi (l'aspect positif) et l'autodépréciation (l'aspect négatif) étaient considérés comme des concepts indépendants 
mais liés qui sous-tendent les sentiments de confiance en soi. L'autodépréciation, la confiance en soi et le fait d'être à l'aise dans son corps annonçaient des aspects différents d'expériences masculines, incluant les attitudes à l'égard du corps, les perceptions des autres, les pressions relatives à la perte de poids et les points de vue entourant la chirurgie esthétique. Par exemple, les participants qui étaient plus à l'aise avec leur corps et manifestaient moins d'autodépréciation étaient plus heureux de la forme et des caractéristiques de leur corps, alors que ceux qui étaient moins à l'aise dans leur corps et avaient moins confiance cherchaient davantage à perdre du poids. De plus, une moins grande confiance en soi était un indicateur important du désir de chirurgie esthétique.

Mots clefs: masculinité; corps; l'estime de soi; autodépréciation; confiance en soi

B

ourdieu (1987) theorized, in his self-reflective analysis on aesthetics and art, that the eye of the 20th century art lover is really a product of history. For Bourdieu, how people view art is a product of all they have learned about art, and the field in which art appears is embedded with all the meanings and value people learn to associate with art over time (Bourdieu 1987). We believe that, in the same sense, how physical appearance is perceived is a product of the field (i.e., the society) in which one is exposed. The field then appears to individuals as immediately endowed with meanings and values. Thus, individuals assess their appearance based on what society has deemed attractive, meaningful, and valuable. As a result, an individual's feelings of self-worth (i.e., self-esteem) may be affected by how that person believes society views their body.

\section{IMAGES OF THE BODY}

Bordo (1993) and Bartky (1990) argued that the body, particularly the female body, is dominated or oppressed through the practices and bodily habits of everyday life. Bordo (1993:16) explains that "culture's grip on the body is a constant, intimate fact of everyday life." This is evident historically, as objectified and sexualized portrayals in advertisements, magazines, and other media primarily portrayed images of women which perpetuated a culture of sexuality and physical appearance (Archer et al. 1983; Courtney and Whipple 1983; Goffman 1979; Lueptow et al. 2001). Images of men, in contrast, were restricted to athletic portrayals and "action shots" or facial photos, where men were individualized agents rather than sexualized marketing tools (Davis 2002; Hall and Crum 1994; Sullivan and O'Conner 1988). Thus, the portrayal of the male body tended to perpetuate more traditional images of masculinity.

Furthermore, Connell (1983:18) examined the social construction of the male body, focusing on "the physical sense of maleness." Ac- 
cording to Connell, the male body is athletic, developed, skilled, large, powerful, forceful, and strong. It occupies space (whereas the female body does not) and is inherently heterosexual. Boys, starting in primary school, are expected to participate in sports. As adults, men are expected to be strong, athletic, and skilled in diverse realms of their life - work, sexuality, and fatherhood. These physically embodied dimensions of masculinity are mixed with the psychological and social dynamics of masculinity, which can lead men to feel they are unable to live up to their image or expectations (Carrigan, Connell, and Lee 1985; Connell 1983). This element of masculinity is complicated by the fact that the masculine identity is constructed during times of social, structural, or personal change (Connell 1995).

More recently, the male body has become increasingly visible and sexualized (Bordo 1999; Gill et al. 2005). For example, advertisements featuring men sexually posed in briefs (e.g., Calvin Klein, Dolce and Gabbana advertisements) have become common place in magazines (e.g., Maxim, Men's Health, GQ, OUT, etc.) and on billboards. Gill et al. (2005:39-40) state that

men's bodies are on display as never before, from the muscular heroes of the cinematic action genre, to the 'sixpacks' who grace the covers of Men's Health, and the 'superwaifs' of contemporary style magazines.

Overall, despite the type of male body being depicted, there is widespread agreement among researchers that a shift has occurred: from being almost invisible, the male body has become hypervisible in the media (Bordo 1999; Gill et al. 2005). The reasons for this shift are contested: different theorists credit different explanations, such as the gay movement, feminism, the style press, consumerism, and changing gender roles (Chapman and Rutherford 1988; Edwards 1997; Featherstone 1991; Gill et al. 2000; 2005; Moore 1988; Mort 1996; Nixon 1996; Simpson 1994). Whatever the reason for this shift, one reality remains evident: the male body in contemporary culture is both highly sexual and highly visible.

For Bourdieu, symbolic domination "is something you absorb like air ... it is everywhere and nowhere, and to escape from that is very difficult" (Bourdieu and Eagleton 1992:115). Media depictions, such as advertisements, have the ability to influence human behaviour - often without our awareness - and influence individual's decisions about what to buy, what to do, and how to look (see Alba 2000; Baurneister 2002; Bargh 2002; Cohen and Chakravarti 1990; Jacoby et al. 1999). In this sense, the hypervisibility of the male body may be a source of symbolic domination shaping how men view their bodies, bringing attention to physical appearances and telling men how they "should" look. 
Overall, the hypervisibility of the male body has played a role in the emergence of a new trend, where men are focusing more attention than ever before on their physical appearance and attractiveness.

\section{The Body and Identity}

Generally, among sociologists, the body is considered central to the image or picture people have of themselves (Goffman 1968; Featherstone 1991). The body is conceptualized as a "project" that is modified and transformed as a fundamental part of self-identity (Shilling 2003). The concept of "body projects" builds on Giddens' (1991) theorization of the reflexive self of high modernity: an era characterized by a decline in the grand narratives of theology, philosophy, and politics that once formed the moral core of, and provided meanings for, peoples lives. These changes combined with the increasing availability of technology for "working on" the body has enabled the physical body to be understood as one domain each individual has the ability to control. "Body project" is the notion that the body is an unfinished entity to be worked upon throughout the life course. It links being attentive to the body's appearance to attempts to utilize the body to construct and maintain a consistent and viable sense of self-identity (Featherstone 1991; Giddens 1991; Shilling 2003). In this sense the body has become an ever-evolving self-reflexive project, central to one's sense of identity (Giddens 1991). Furthermore, the body is an objectified reality whose current appearance is determined by the narrative of self under construction (Giddens 1991). In this sense, bodies are constantly becoming, being made and remade to reflect one's lived reality or the reality one aims to acquire. Thus, "bodies not only become objects for human management and reconfiguration but are increasingly central to one's identity" (Budgeon 2003:37).

Different appearances of the body - dress, body shape, size, and style - correspond to different versions of the self. According to Bourdieu (1978), social status and class shape one's relationship with the body. Bourdieu (1978:838) explained that the working classes viewed the body primarily as a means to an end, while the privileged classes were more likely to "treat the body as an end in itself" with a greater focus on physical appearance. Thus, while the body may be viewed as a project, social differences provide some individuals with greater means to invest in the body as a physical source of self-identification. Overall, as Gill et al. (2005) argue, in late modernity, secure and stable self-identity is no longer an automatic derivative of social class and status; consequently, some individuals are turning to their bodies as the basis of identity.

Considering the role of the body in self-identification, financially and physically investing in the body is equivalent to constructing one's sense 
of self. In affluent Western societies, with the rise of individualism and consumerism, individuals are increasingly pressured to transform and "improve" their bodies as a part of their identity (Giddens 1991; Shilling 2003). The body is viewed as a means of self-expression necessitating investment and encouraging consumerism (Featherstone 1991). Gullette (1994) explains that men are increasingly using cosmetics, body modification, and fashion in an attempt to increase their physical attractiveness, which is a cultural trap that women have been experiencing for years. Thus, men too are falling prey to consumer capitalism, particularly in the areas of aesthetics and fashion (Featherstone 1991).

\section{Appearance Issues}

Grogran (1999) found that the hypervisibility of men in the media has generated concerns regarding the health, self-esteem, and body image of young men and boys. Men are presented with images that pressure them to look a certain way and have a particular body shape and size (Trujillo 2000). The bodies presented are not all the same; they differ depending on the genre of media in which they are depicted. For example, some idealized portrayals are highly muscular, whereas others are incredibly skinny. Some are toned, some are buff, and some are modelesque. The commonality among the different bodies deemed ideal by the media is that none are overweight, they have hair in the appropriate places and not in others (i.e., no baldness or back hair), and they are all fashionable.

According to Bourdieu (1984), the body reflects social class by situating one's social status, reflecting one's degree of sophistication and the formation of one's habitus. Habitus, for Bourdieu (1984; 1990), is derived from social conditioning and refers to the socially acquired tendencies or predispositions that are manifested in the opinions, perspectives, and manners of being (i.e., how one walks, carries oneself, etc.) of each individual. Thus, how people choose to present themselves and their body is not really determined by choice; individuals, through appraising different social situations, fall into the appropriate verbal and physical behaviours and presentations (Bourdieu 1990). The manner in which one perceives one's body corresponds to the version of self that emerges from the social setting within which one is situated. Moreover, the preferred body image is determined by the society in which one takes part and what is considered ideal or attractive within that social setting. For most men, the preferred body image is an unachievable ideal, and being bombarded by these unachievable images negatively impacts men's psychological well-being (Gill et al. 2005). 
One negative psychological consequence of these unachievable images is body dysmorphic disorder (BDD), which stems from a distorted perception of the body and its appearance (Rowan 2004). American data suggests that up to $15 \%$ of all male cosmetic surgery patients suffer from this disorder (Bryant 2003). In 2006, appropriately 1.1 million men had cosmetic procedures in the United States $(256,000$ invasive cosmetic surgeries and 851,000 minimally invasive). This means that an estimated 165,000 of these patients suffer from BDD (American Society of Plastic Surgeons 2007). In fact, there is concern that "BDD will become increasingly common over the next few years as men face more of these unrealistic pressures to look better" (Pope et al. 2000:2).

Another negative psychological consequence of these media depictions is feeling judged by others. In their study of British men, Gill et al. (2005:56) found that "the look of the body is made to stand for the entire identity and assumed lifestyle." When the body is viewed as an indicator of self-control and self-discipline, weight gain often generates disapproval and negative societal judgment because it is associated with a lack of self-control (Bordo 1993). Research has identified a number of cases where men and women have felt negatively judged by others and that others disliked them, due to their weight, body, or features (Averett and Korenman 1996; Ross 1994; Wiederman and Hurst 1998). The literature documents how such perceived judgments can have a negative effect on one's self-esteem (Hayes and Ross 1986; Hoelter 1984; Mead 1934).

Research shows that dissatisfaction with body weight is also related to low self-esteem (Hesse-Biber 1996; Ross 1994). Budgeon (2003) found that, among women, body dissatisfaction stemmed from perceived pressures from peers, parents, and society. Similarly, men have reported being teased and monitored by friends when they begin putting on weight (Gill et al. 2005). External pressures to lose weight from family, significant others, and colleagues may cause feelings of bodily dissatisfaction, low self-esteem, and a negative self-image (Budgeon 2003; HaworthHoeppner 2000; Ross 1994).

Evidence suggests that low self-esteem and feeling judged on one's physical appearance may lead individuals to consider cosmetic surgery (Budgeon 2003; Davis 2002; Sullivan 2001). In the past, men opting for elective surgery have cited reasons such as delaying the aging process, "working on" their appearance, and increasing their self-confidence (Davis 2002; Featherstone 1991; Gullette 1994). Although the bodily perceptions of both men and women are influenced by sociocultural pressures, the literature mainly documents how women view and modify their bodies to correspond to the dominant images of femininity (see Bartky 1990; Ehrenreich and English 1978; Wolf 1991). Relatively lit- 
tle work has investigated these influences on men. Past norms dictated that men should not be concerned about their appearance, which was considered a feminine characteristic, so men may have more difficulty discussing these issues (Davis 2002). This inability to express their concerns may lead to even greater negative psychological consequences. As Davis (2002:60) puts it, "the male cosmetic surgery recipient crosses the border of what is considered acceptable masculine demeanour. He acts like a woman." Thus, whether a man would even consider cosmetic surgery may depend upon his level of self-esteem or comfort with the body.

\section{Self-Esteem: Self-Confidence and Self-Deprecation}

Research on the body and body modification has found consequences for self-esteem (e.g., Budgeon 2003; Davis 2002; Grogran 1999; HaworthHoeppner 2000; Hayes and Ross 1986; Hesse-Biber 1996; Hoelter 1984; Mead 1934; Ross 1994; Sullivan 2001). Research outside of the body literature has found that the effects of self-esteem can be reciprocal. For example, not only does low self-esteem lead to delinquent behaviour, but delinquent behaviour can increase self-esteem (Rosenberg et al. 1989). The body literature has predominantly investigated the consequences of the body and body modifications on self-esteem; the current research investigates the reciprocal aspect of self-esteem to shed light on the influences of self-esteem on the body and body modification.

Self-esteem is an attitude about the self, the positive or negative feelings one has about the self, or one's feelings of self-worth (e.g., Owens 1993; Rosenberg 1979). As one can have differing feelings toward different aspects of a particular concept (e.g., one could like the benefits of exercising but not like taking the time to exercise), people can have differing feelings toward the self (e.g., Owens 1993; Rosenberg et al. 1995). In terms of the self, self-esteem researchers call the positive aspects or feelings self-confidence and the negative aspects or feelings self-deprecation (e.g., Owens 1993; Rosenberg et al. 1995). Furthermore, Owens (1993) empirically demonstrated the existence of these two separate but related aspects of self-esteem. The body literature, however, predominantly deals with global self-esteem, i.e., an individual's positive or negative attitude toward the self as a totality (Rosenberg et al. 1995), rather than these two separate but distinct elements of self-esteem. Thus, the current research contributes to the body literature by investigating the specific contributions of self-confidence versus self-deprecation and how these two aspects of self-esteem are different from one's overall comfort with one's body. 


\section{Current Study}

Sociologists generally accept that the body is central to how people picture themselves (Featherstone 1991; Goffman 1968). Yet, how individuals perceive their body and what body they would like to promote is not simply due to intrinsic notions of self-presentation or embodiment. Habitus may also play a role in shaping how one perceives one's body and what one considers attractive. Habitus, for Bourdieu $(1984 ; 1990)$, is derived from social conditioning and has social origins that are shaped via cultural and social exposures, which in turn shape the social construction of reality (Bourdieu 1984). Thus, how one presents oneself or behaves is not determined by choice. Instead, individuals appraise different social settings and fall into the verbal and physical behaviours appropriate to their habitus (Bourdieu 1990). Factors such as one's level of self-confidence, self-deprecation, and overall comfort with one's body also derive from the habitus and experiences within the habitus. Since men's attitudes and perspective of their body, as well as their physical appearance, are reflections of their habitus, we test how self-esteem (self-confidence vs. self-deprecation) and comfort with the one's body affect bodily perspective.

Compared to women, relatively little research has specifically focused on men's views of the male body. The purpose of the current study was to more fully investigate men's attitudes and perspectives regarding their physical appearance. As most current work on masculinity has taken a qualitative approach (see Davis 2002; Gill et al. 2000; 2005), we add to this literature by quantitatively testing a number of qualitative factors evident in one's habitus, such as attitudes about body shape, perceptions of others, pressures to lose weight, and perspectives regarding cosmetic surgery - as well as exploring social barriers that men might experience due to their appearance. We test these concepts to determine whether they extend to Canadian men as well. Previous research has alluded to the role of self-esteem and/or self-confidence in body perceptions (Gill et al. 2000; 2005); the current study specifically tests whether the positive aspects of self-esteem (self-confidence), the negative aspects of self-esteem (self-deprecation), and/or a general sense of comfort with the body drives these effects in men.

\section{METHOD}

\section{Participants}

One hundred and three Canadian men volunteered to participate in this study. Respondents were recruited for participation in four ways. First, 
business cards advertising the study were distributed to men in shopping centres and coffee shops in the greater Toronto area (GTA). Second, students from a small Canadian university were also invited to participate. Third, an advertisement for the study was placed in FAB, a free homosexual publication circulating in the GTA. Last, snowball sampling was used to find additional men who had undergone or were considering cosmetic surgery.

Ages of participants ranged from 18-50. The majority of the sample reported their sexuality as heterosexual $(n=89)$; homosexual $(n=9)$, bisexual $(n=2)$ and unsure $(n=2)$ were reported less frequently. One respondent did not state his sexuality. Respondents included university students, executives, professionals, members of the armed forces, and employees of the service industry. All of the respondents lived in Toronto or the greater Toronto area. As an incentive, all participants had the opportunity to be included in a draw for a $\$ 100$ gift certificate.

All participants were asked if they had ever undergone a cosmetic surgery procedure. Two respondents reported that they had undergone cosmetic surgery; two other participants were unsure if their procedure was considered cosmetic surgery. Without being asked, over $15 \%$ $(n=14)$ of participants stated they were considering, had thought about, or would have a surgical procedure in the future.

\section{Materials}

An 18 item online survey was created to assess men's views of their personal appearance, their body, and their feelings about cosmetic surgery. The independent variables were self-esteem (self-confidence and selfdeprecation) and body comfort, whereas the dependent variables clustered into themes of body shape, perception by others, social barriers, weight loss, and cosmetic surgery.

\section{Independent variables}

The independent variables were designed to measure self-esteem and comfort with the body in predicting how men feel about their appearance and cosmetic surgery. Two items assessed self-confidence: "I have been living without confidence for as long as I can remember" and "I am confident" (reverse coded). These two items were averaged together to create a low self-confidence variable. This means that high scores indicate low confidence and low scores indicate high confidence. Although this may seem at first counterintuitive, we wished to keep the self-confidence and self-deprecation items consistent: all high scores have a negative meaning (negative self-esteem and negative view of self) and all 
low scores have a positive meaning (positive self-esteem and positive view of self). The item "I have low self-esteem" measured the extent to which participants engaged in self-deprecation. Again, high scores equate to high self-deprecation (negative self-esteem) and low scores equate to low self-deprecation (positive self-esteem). "I am comfortable with my body" assessed general comfort with the body: high scores correspond to greater comfort with the body and low scores correspond to less comfort with the body. For each of these items, participants were asked to indicate the response that best represented how they felt, where $\mathrm{SD}=$ "strongly disagree," $\mathrm{D}=$ "disagree," $\mathrm{N}=$ " neither disagree nor agree/ neutral," A="agree," and SA="strongly agree." The low number of items in each variable (two of these variables are one item only) made it impossible to assess internal consistency reliability coefficients.

\section{Dependent variables}

There were 13 close-ended items assessing dependent variables, which were divided into 5 main themes: body shape, perception by others, social barriers, weight loss, and cosmetic surgery (Table 1). These items were measured using the same scale as the independent variables. The "body shape" items were created to explore issues of BDD that might be more generally experienced, such as not liking a particular feature or the shape of one's face. The "perception by others" items were designed to capture feelings of judgment due to one's appearance. As judgments by others may cause avoidance of social situations where further judgments might occur, we also created a few "social barriers" items. The "weight loss" items focused on pressures to lose weight and the "cosmetic surgery" items were designed to explore perspectives on cosmetic surgery. As each item looked at a unique factor of participants' experiences with the body, it was not possible to run an internal consistency analysis.

Finally, there was an additional open-ended cosmetic surgery item that asked participants how they felt about cosmetic surgery in general. Specifically, each participant was asked to "please describe your feelings towards cosmetic surgery." Respondents were not restricted by time or space in responding to the open-ended question.

\section{Procedure}

The survey was conducted electronically over a period of 8 months, from November 2006 to July 2007. Considering the private nature of many of the items, the Internet-based questionnaire provided an anonymous medium for learning about men's views and experiences. On average, participants required 25 minutes to complete the questionnaire. After- 
Table 1. Questionnaire Items Organized by Themes: Means, Standard Deviations, and N-Size

\begin{tabular}{|c|c|c|c|c|}
\hline Theme & Item & Mean & $S D$ & $N$ \\
\hline \multirow{3}{*}{ The body } & I like my body's shape. & 3.46 & 0.897 & 102 \\
\hline & I like the shape of my face. & 3.90 & 0.768 & 101 \\
\hline & $\begin{array}{l}\text { I am embarrassed by one of my body parts or } \\
\text { features. }\end{array}$ & 2.87 & 1.248 & 102 \\
\hline \multirow{3}{*}{$\begin{array}{l}\text { Percep- } \\
\text { tion by } \\
\text { others }\end{array}$} & $\begin{array}{l}\text { I feel I am mistakenly considered lazy because } \\
\text { of my physical appearance. }\end{array}$ & 2.24 & 1.045 & 102 \\
\hline & $\begin{array}{l}\text { I feel I am judged by others because of my } \\
\text { physical appearance. }\end{array}$ & 3.64 & 1.060 & 102 \\
\hline & My appearance decreases my self-confidence. & 2.39 & 1.109 & 102 \\
\hline \multirow{3}{*}{$\begin{array}{l}\text { Social } \\
\text { barriers }\end{array}$} & $\begin{array}{l}\text { My appearance makes me uncomfortable in } \\
\text { social situations. }\end{array}$ & 2.05 & .099 & 101 \\
\hline & My appearance makes me uncomfortable dating. & 2.20 & 1.178 & 102 \\
\hline & $\begin{array}{l}\text { I am unable to participate in certain activities, } \\
\text { (i.e. going swimming without a shirt) because I } \\
\text { am embarrassed by my physical appearance. }\end{array}$ & 2.24 & 1.212 & 102 \\
\hline \multirow{2}{*}{$\begin{array}{l}\text { Weight } \\
\text { loss }\end{array}$} & I put pressure on myself to lose weight. & 2.56 & 1.459 & 100 \\
\hline & I feel pressured by my family to lose weight. & 1.67 & 1.001 & 101 \\
\hline \multirow{2}{*}{$\begin{array}{l}\text { Cosmetic } \\
\text { surgery }\end{array}$} & $\begin{array}{l}\text { I would consider cosmetic surgery to improve } \\
\text { my physical appearance. }\end{array}$ & 2.05 & 1.236 & 101 \\
\hline & $\begin{array}{l}\text { I feel having cosmetic surgery would improve } \\
\text { my life. }\end{array}$ & 1.86 & 1.044 & 102 \\
\hline
\end{tabular}

wards, participants were thanked for their participation, provided with written feedback about the objectives of the study and directed to additional academic and professional resources relating to appearance, cosmetic surgery, self-esteem, and identity issues.

\section{Results AND DiscusSion}

Using the theoretical framework of Bourdieu, multiple regressions were conducted. Self-confidence, self-deprecation, and comfort with the body are consequences of one's habitus. Due to the reciprocal nature of self-esteem (e.g., Rosenberg et al. 1989), we use self-confidence, self-deprecation, and comfort with the body to predict men's attitudes toward the body, their beliefs about how others perceive them, the barriers they perceive due to their appearance, their perspective on weight loss, and their opinions about cosmetic surgery. Specifically, these analyses were designed to further investigate how self-esteem and body comfort relate to men's experiences of their habitus and their relationship with their bodies, especially the unique contributions of self-confidence versus self-deprecation. 
We used thematic analysis to investigate the open-ended item. Participants with missing data were removed from the affected analyses.

\section{Body Shape}

The independent variables significantly predicted the extent to which participants liked the shape of their bodies, $F(3,97)=18.23, p<.001$ $\left(R^{2}=.36\right)$, liked the shape of their faces, $F(3,96)=12.49, p<.001\left(R^{2}=.28\right)$, and were embarrassed by a body part or feature, $F(3,97)=12.14, p<.001$ $\left(R^{2}=.27\right)$. Thus, $36 \%$ of the variance in participants' responses about how much they liked the shape of their face was accounted for simply by their level of self-confidence, self-deprecation, and comfort with their bodies. Similarly, $28 \%$ of the variability in participants' responses about liking the shape of their face was accountable to self-confidence, self-deprecation, and comfort with the body, whereas these variables explained $27 \%$ of the variance in being embarrassed by a particular body part or feature. This suggests that self-esteem (both self-confidence and self-deprecation) and comfort with the body do indeed affect how men perceive their own bodies.

There were unique findings for these variables as well (Table 2). As expected, participants' level of comfort with their own bodies was a significant unique predictor. Participants who were more comfortable with their bodies were significantly more likely to like their body shape, $t(97)=6.24, p<.001$, significantly more likely to like the shape of their

Table 2. Unique Contributions of Confidence, Self-Esteem and Body Comfort on Body Shape Items

\begin{tabular}{|c|c|c|c|c|c|}
\hline \multicolumn{6}{|c|}{ I like my body's shape } \\
\hline & $B$ & Std. Error & Beta & $t$ & Sig. \\
\hline (Constant) & 1.136 & 0.526 & & 2.161 & 0.033 \\
\hline Low self-confidence & -0.201 & 0.120 & -0.191 & -1.675 & 0.097 \\
\hline High self-deprecation & 0.135 & 0.090 & 0.169 & 1.509 & 0.135 \\
\hline Comfortable with body & 0.670 & 0.107 & 0.568 & 6.239 & 0.000 \\
\hline \multicolumn{6}{|c|}{ I like the shape of my face } \\
\hline & $B$ & Std. Error & Beta & $t$ & Sig. \\
\hline (Constant) & 3.245 & 0.483 & & 6.720 & 0.000 \\
\hline Low self-confidence & -0.032 & 0.109 & -0.036 & -0.294 & 0.769 \\
\hline High self-deprecation & -0.210 & 0.082 & -0.303 & -2.560 & 0.012 \\
\hline Comfortable with body & 0.317 & 0.099 & 0.307 & 3.191 & 0.002 \\
\hline \multicolumn{6}{|c|}{ I am embarrassed by one of my body parts or features } \\
\hline & $B$ & Std. Error & Beta & $t$ & Sig. \\
\hline (Constant) & 2.894 & 0.781 & & 3.706 & 0.000 \\
\hline Low self-confidence & 0.259 & 0.178 & 0.176 & 1.454 & 0.149 \\
\hline High self-deprecation & 0.291 & 0.133 & 0.261 & 2.186 & 0.031 \\
\hline Comfortable with body & -0.328 & 0.160 & -0.200 & -2.055 & 0.043 \\
\hline
\end{tabular}


face, $t(96)=3.19, p<.01$, and significantly less likely to be embarrassed by a body part or feature, $t(97)=-2.06, p<.05$, than participants who were less comfortable with their bodies. Self-deprecation also accounted for unique variance. Participants reporting higher self-deprecation were significantly less likely to like the shape of their own face, $t(96)=-2.56$, $p<.05$, and significantly more likely to be embarrassed by a body part or feature, $t(97)=2.19, p<.05$, than participants reporting lower selfdeprecation. Confidence did not significantly account for unique variance among the body items.

Among men, comfort with one's body was the best predictor of their overall feelings towards their body shape. Self-deprecation was also found to uniquely predict how men felt about their body shape. Meanwhile self-confidence, surprisingly, was not a unique predictor. These findings correspond to past literature on the importance of self-esteem, particularly in relation to personal bodily satisfaction or dissatisfaction (Hayes and Ross 1986; Hoelter 1984; Ross 1994). Furthermore, our findings suggest the value of separating self-confidence and self-deprecation when investigating attitudes towards the body. Our findings indicate that self-deprecation specifically (i.e., the negative aspect of self-esteem) is an important determinant of whether men come to value and appreciate their body shape. Considering cultural and social exposure shapes one's habitus (Bourdieu 1984), it seems that Canadian men's habitus is affected by negative self feelings and body comfort and this in turn influences how men see and feel about their bodies.

\section{Perception by Others}

Together, the three independent variables predicted the degree to which participants felt judged due to their physical appearance, $F(3,97)=3.48$, $p<.05\left(R^{2}=.10\right)$; thought they were misconstrued as lazy, $F(3,97)=6.78$, $p<.001\left(R^{2}=.17\right)$; and believed their appearance decreased their selfconfidence, $F(3,97)=19.42, p<.001\left(R^{2}=.38\right)$. All three analyses were statistically significant. Simply knowing a participant's level of selfconfidence, self-deprecation, and body comfort accounted for $10 \%$ of the variance in responses about feeling judged due to appearance and $17 \%$ of the variance in responses about being misconstrued as lazy. Perhaps unsurprisingly, these variables accounted for $38 \%$ of the variance regarding responses about appearance decreasing self-confidence. These results suggest that men's attitudes towards their body as well as their perception of their body is, indeed, affected by self-esteem and body comfort, which are derivatives of their habitus. 
Table 3. Unique Contributions of Confidence, Self-Esteem and Body Comfort on Perception by Others Items

\begin{tabular}{|c|c|c|c|c|c|}
\hline \multicolumn{6}{|c|}{ I feel I am judged by others because of my physical appearance } \\
\hline & $B$ & Std. Error & Beta & $t$ & Sig. \\
\hline (Constant) & 3.303 & 0.738 & & 4.476 & 0.000 \\
\hline Low self-confidence & 0.187 & 0.168 & 0.150 & 1.109 & 0.270 \\
\hline High self-deprecation & 0.140 & 0.126 & 0.149 & 1.117 & 0.267 \\
\hline Comfortable with body & -0.099 & 0.151 & -0.071 & -0.656 & 0.514 \\
\hline \multicolumn{6}{|c|}{ I feel I am mistakenly considered lazy because of my physical appearance } \\
\hline & $B$ & Std. Error & Beta & $t$ & Sig. \\
\hline (Constant) & 2.017 & 0.697 & & 2.892 & 0.005 \\
\hline Low self-confidence & 0.546 & 0.159 & 0.444 & 3.433 & 0.001 \\
\hline High self-deprecation & -0.150 & 0.119 & -0.161 & -1.266 & 0.209 \\
\hline Comfortable with body & -0.172 & 0.142 & -0.125 & -1.208 & 0.230 \\
\hline \multicolumn{6}{|c|}{ My appearance decreases my self-confidence } \\
\hline & $B$ & Std. Error & Beta & $t$ & Sig. \\
\hline (Constant) & 1.753 & 0.643 & & 2.728 & 0.008 \\
\hline Low self-confidence & 0.436 & 0.147 & 0.334 & 2.973 & 0.004 \\
\hline High self-deprecation & 0.238 & 0.109 & 0.241 & 2.177 & 0.032 \\
\hline Comfortable with body & -0.223 & 0.131 & -0.153 & -1.695 & 0.093 \\
\hline
\end{tabular}

Although none of the variables uniquely predicted feeling judged by others (Table 3), participants reporting less self-confidence were significantly more likely to believe that others considered them lazy because of their appearance, $t(97)=3.43, p<.001$, and that their appearance decreased their self-confidence, $t(97)=2.97, p<.01$, than those reporting more confidence. In addition, participants reporting higher self-deprecation were also significantly more likely to report that their appearance decreased their self-confidence than their lower self-deprecation peers, $t(97)=2.18$, $p<.05$. Body comfort did not significantly account for unique variance on the items related to other people's perceptions. This may be because comfort with one's body is a personal feeling that others may be unaware of, or men may understand that their own bodily discomforts are personal and often remain unrecognized by the population at large. Moreover, since social norms dictate that men should not be concerned about their appearance (Davis 2002) and, consequently, should not express such concerns nor experience discomfort with their body, men may feel that others in society are unaware of the potential for men to experience discomfort with their body.

\section{Social Barriers}

The independent variables were able to significantly predict variance in participant scores regarding how their appearance affected their willingness to participate in certain activities, $F(3,97)=13.02, p<.001\left(R^{2}=.29\right)$, 
their comfort in social situations, $F(3,96)=22.43, p<.001\left(R^{2}=.41\right)$, and their comfort dating in particular, $F(3,97)=25.55, p<.001\left(R^{2}=.44\right)$. Knowing the self-confidence, self-deprecation, and body comfort of these participants accounted for $29 \%$ of the variance in their willingness to participate in particular activities, $41 \%$ of the variance regarding their comfort in social situations, and $44 \%$ of the variance in their responses regarding their comfort when dating. These large numbers suggest that the self-esteem and body comfort aspects of one's habitus play a large role in shaping men's views of physical appearance and the body in society.

As for unique contributions (Table 4), participants' inability to participate in particular activities due to embarrassment of their physical appearance was significantly predicted by self-confidence, $t(97)=3.11$, $p<.01$, and body comfort, $t(97)=-3.53, p<.001$; participants who were lower in confidence and less comfortable with their bodies agreed more strongly than participants who were more confident and more comfortable with their bodies.

All three variables uniquely predicted participants' discomfort in social situations. Participants who were less self-confident, $t(96)=2.94$, $p<.01$, higher in self-deprecation, $t(96)=2.38, p<.05$, and less comfortable with their bodies, $t(96)=-2.16, p<.05$, reported that their appearance made them significantly more uncomfortable in social situations than

Table 4. Unique Contributions of Confidence, Self-Esteem and Body Comfort on Social Barriers Items

I am unable to participate in certain activities, (i.e., going swimming without a shirt) because I am embarrassed by my physical appearance

\begin{tabular}{|c|c|c|c|c|c|}
\hline & $B$ & Std. Error & Beta & $t$ & Sig. \\
\hline (Constant) & 3.347 & 0.751 & & 4.458 & 0.000 \\
\hline Low self-confidence & 0.532 & 0.171 & 0.373 & 3.106 & 0.002 \\
\hline High self-deprecation & -0.124 & 0.128 & -0.115 & -0.970 & 0.334 \\
\hline Comfortable with body & -0.541 & 0.153 & -0.339 & -3.529 & 0.001 \\
\hline \multicolumn{6}{|c|}{ My appearance makes me uncomfortable in social situations } \\
\hline & $B$ & Std. Error & Beta & $t$ & Sig. \\
\hline (Constant) & 1.608 & 0.617 & & 2.607 & 0.011 \\
\hline Low self-confidence & 0.416 & 0.142 & 0.323 & 2.937 & 0.004 \\
\hline High self-deprecation & 0.252 & 0.106 & 0.259 & 2.381 & 0.019 \\
\hline Comfortable with body & -0.272 & 0.126 & -0.189 & -2.157 & 0.034 \\
\hline \multicolumn{6}{|c|}{ My appearance makes me uncomfortable dating } \\
\hline & $B$ & Std. Error & Beta & $t$ & Sig. \\
\hline (Constant) & 2.563 & 0.644 & & 3.977 & 0.000 \\
\hline Low self-confidence & 0.270 & 0.147 & 0.195 & 1.839 & 0.069 \\
\hline High self-deprecation & 0.338 & 0.110 & 0.323 & 3.085 & 0.003 \\
\hline Comfortable with body & -0.459 & 0.132 & -0.296 & -3.482 & 0.001 \\
\hline
\end{tabular}


did their peers. Similar patterns were obtained for dating, where participants who were higher in self-deprecation, $t(97)=3.09, p<.01$, and less comfortable with their bodies, $t(96)=-3.48, p<.001$, reported that their appearance made them more uncomfortable dating than did their peers. There was a marginal finding for self-confidence; participants who were less confident tended to be less comfortable dating as well, $t(97)=1.84$, $p<.07$.

Once again, comfort with one's body was the best unique predictor of men's willingness to participate in certain activities, their comfort in social situations, and their comfort with dating. Self-confidence and selfdeprecation were both unique predictors of most social barrier items. Yet, importantly here, self-confidence, not self-deprecation, accounted for variance in the inability of participants to participate in particular activities due to being embarrassed by their physical appearance, while self-deprecation, not self-confidence, accounted for the variance in comfort with dating. Our findings support the notion that the differing aspects of self-esteem should be investigated as distinct concepts (e.g., Owens 1993; Rosenberg et al. 1995) in order to more fully understand the impact of self-esteem on the body. Yet, in looking at appearance in relation to perceived social barriers, overall comfort with the body is more important than self-esteem in uniquely predicting such factors.

Considering the influential role of the physical body in identity construction, men who experience bodily dissatisfaction may feel socially awkward due to the cultural and societal exposures in their habitus that stress the importance of physical attraction. As a result, the personal reality of men - particularly regarding their bodily perceptions - may prevent them from fully participating in society.

\section{Weight Loss}

The independent variables significantly predicted the extent to which participants felt pressured by themselves, $F(3,95)=8.68, p<.001$ $\left(R^{2}=.22\right)$, and their families, $F(3,96)=9.00, p<.001\left(R^{2}=.22\right)$, to lose weight. Self-confidence, self-deprecation, and body comfort explained $22 \%$ of the variance in participants' responses about putting pressure on themselves to lose weight. These variables also explained $22 \%$ of the variance in participants' reports of the pressure their families placed on them to be thinner. It appears that self-esteem and body comfort influence the perspectives of men in relation to ideal body size.

As one would expect, comfort with the body significantly predicted unique variance for these items; participants who reported less comfort with their bodies were significantly more likely to put pressure on them- 
selves to lose weight, $t(95)=-3.71, p<.001$ and to feel pressure from their families as well, $t(96)=-3.97, p<.001$, than participants who reported greater body comfort. In addition, participants who reported lower selfconfidence were also significantly more likely to put pressure on themselves to lose weight than were participants who reported higher selfconfidence, $t(95)=1.98, p<.05$. Self-deprecation did not uniquely predict variance in the weight loss items (Table 5).

Body comfort, once again, was the best predictor for the weight loss variables. Self-confidence - not self-deprecation - uniquely predicted the extent to which participants felt pressured by themselves and their families to lose weight. This is further evidence that self-deprecation and self-confidence are important distinct aspects of self-esteem among Canadian men.

When investigating the factors that undermine confidence in young women, Budgeon (2003) found that social pressures from peers, parents, society, and - most predominantly - media representations affected not only their confidence, but their ability to feel good about themselves. These social pressures often originate in one's habitus and influence one's overall persona, at times without ever being acknowledged (Bourdieu 1978). We obtained similar findings among men. We found that Canadian men lower in self-confidence put more pressure on themselves, and felt more pressure by others, to lose weight than men higher in selfconfidence. This lack of confidence may be related to a variety of factors, including the negative qualities men may identify with being "fat" and issues surrounding their perceived lack of "self-discipline." Studies have found that individuals associate laziness, sloppiness, meanness, and stupidity with overweight individuals (Lerner 1969; Lerner and Korn 1972; Ross 1994). Thus, considering the link between body and identity, men

Table 5. Unique Contributions of Confidence, Self-Esteem and Body Comfort on Weight Loss Items

\begin{tabular}{|c|c|c|c|c|c|}
\hline \multicolumn{6}{|c|}{ I put pressure on myself to lose weight } \\
\hline & $B$ & Std. Error & Beta & $t$ & Sig. \\
\hline (Constant) & 4.637 & 0.946 & & 4.899 & 0.000 \\
\hline Low self-confidence & 0.433 & 0.219 & 0.253 & 1.982 & 0.050 \\
\hline High self-deprecation & -0.189 & 0.162 & -0.146 & -1.164 & 0.247 \\
\hline Comfortable with body & -0.716 & 0.193 & -0.377 & -3.710 & 0.000 \\
\hline \multicolumn{6}{|c|}{ I feel pressured by my family to lose weight } \\
\hline & $B$ & Std. Error & Beta & $t$ & Sig. \\
\hline (Constant) & 3.251 & 0.649 & & 5.010 & 0.000 \\
\hline Low self-confidence & 0.219 & 0.149 & 0.179 & 1.468 & 0.145 \\
\hline High self-deprecation & -0.045 & 0.111 & -0.049 & -0.405 & 0.686 \\
\hline Comfortable with body & -0.529 & 0.133 & -0.393 & -3.967 & 0.000 \\
\hline
\end{tabular}


may feel that they embody such negative characteristics because of their body size and their experiences within the habitus.

In addition, weight pressures among men may be related to feelings of inferiority or failure because of a perceived lack of "self-discipline" in controlling their weight in the first place. Research on women suggests that women who feel overweight think they need to take responsibility for their body shape and size, via diet and exercise (Budgeon 2003; West 2000; Wolf 1991). Our findings suggest that men may experience similar pressures. With an increasing number of men turning to high-risk weight management practices - extensive dieting, obsessive exercising, disordered eating, or surgical interventions (i.e., stomach stapling or liposuction) - this trend merits future study and awareness (Davis 1997; 2002; Haworth-Hoeppner 2000; Hesse-Biber 1996).

\section{Cosmetic Surgery}

Together, the independent variables significantly predicted the degree to which participants would consider cosmetic surgery to improve their physical appearance, $F(3,96)=5.71, p<.001\left(R^{2}=.15\right)$, and to what extent they felt that cosmetic surgery would improve their lives, $F(3,97)=3.85$, $p<.05\left(R^{2}=.11\right)$. Although the variance explained is not overwhelming, self-confidence, self-deprecation, and body comfort did account for $15 \%$ of the variability in responses about considering cosmetic surgery to improve physical appearance and $11 \%$ of the variability in responses about whether cosmetic surgery would improve their lives. Self-esteem and body comfort appear to be important components of men's habitus, with consequences for their attitudes and beliefs about cosmetic surgery. As for the influence of each independent variable (Table 6), self-confidence uniquely predicted variance in willingness to undergo cosmetic surgery

Table 6. Unique Contributions of Confidence, Self-Esteem and Body Comfort on Cosmetic Surgery Items

\begin{tabular}{|c|c|c|c|c|c|}
\hline \multicolumn{6}{|c|}{ I would consider cosmetic surgery to improve my physical appearance } \\
\hline & $B$ & Std.Error & Beta & $t$ & Sig. \\
\hline (Constant) & 1.967 & 0.834 & & 2.358 & 0.020 \\
\hline Low Self-Confidence & 0.422 & 0.193 & 0.289 & 2.187 & 0.031 \\
\hline High Self-Deprecation & 0.021 & 0.143 & 0.019 & 0.148 & 0.883 \\
\hline Comfortable with Body & -0.236 & 0.170 & -0.146 & -1.384 & 0.169 \\
\hline \multicolumn{6}{|c|}{ I feel having cosmetic surgery would improve my life } \\
\hline & $B$ & Std. Error & Beta & $t$ & Sig. \\
\hline (Constant) & 1.498 & 0.722 & & 2.075 & 0.041 \\
\hline Low Self-Confidence & 0.254 & 0.165 & 0.208 & 1.545 & 0.126 \\
\hline High Self-Deprecation & 0.094 & 0.123 & 0.101 & 0.761 & 0.448 \\
\hline Comfortable with Body & -0.102 & 0.147 & -0.075 & -0.693 & 0.490 \\
\hline
\end{tabular}


scores; participants reporting lower levels of confidence were significantly more likely to consider using cosmetic surgery to improve their appearance than were more confident participants, $t(96)=2.19, p<.05$. No other variables uniquely predicted participants' responses to the cosmetic surgery items. For willingness to consider cosmetic surgery, self-confidence is the only significant predictor. It is not overall comfort with the body that determines whether people will think about cosmetic surgery as an option, nor is it self-deprecation.

\section{Thematic Analysis}

When participants were asked to comment on their feelings toward cosmetic surgery, nine themes emerged. These nine themes can be categorized as for or against such procedures. Themes supportive of cosmetic surgery included: improving self-esteem, fixing physical deformities, personal choice, and financial barriers. Themes against cosmetic surgery consisted of: importance of being happy with and accepting one's "natural" body, moral condemnation of cosmetic surgery, vanity, laziness, cost, and perceived danger. For these responses, grammatical and spelling errors were corrected.

\section{Supportive of cosmetic surgery}

Over twenty participants were supportive of cosmetic surgery if it had the potential to increase one's self-esteem. For example, participants said that "if surgery could boost their esteem they should do it" and "if it will genuinely boost one's confidence to the point where they have a better quality of life, then so be it." Noteworthy here is participants' use of the word "they." Although the men are making supportive claims of cosmetic surgery, this more feminine form of body modification is kept socially distant from the self by making these claims on behalf of others. These sentiments could be interpreted in two different ways: (1) Canadian men would not consent to cosmetic surgeries for themselves, but they do see it as a viable option for others, or (2) Canadian men would consent to cosmetic surgery for themselves but are not willing to admit to it and instead talk in terms of a hypothetical other. Further research is needed to distinguish between these two possibilities.

The second emergent theme was that men were particularly supportive of having cosmetic surgery to "fix" physical deformities from birth defects, accidents, or other such events. These responses represented fifteen of the statements made by participants. An example of typical responses include: "I believe that cosmetic surgery is a good thing for those who get into accidents, and need reconstruction" and "I think it is 
necessary for deformities/surgical restructuring, and if it helps a person's self-esteem." Importantly, men tended to be especially supportive of cosmetic surgery to "fix" physical imperfections if they thought it would also improve self-esteem. Thus, self-esteem seemed to be a re-emerging theme. Another re-emerging theme is the distinction of self versus other. Here, men seem to be supportive of cosmetic surgery for other men who have experienced physical deformities. They do not, however, explicitly state whether they themselves would choose to have cosmetic surgery under similar conditions.

Other categories include personal choice and financial barriers. The thematic category of personal choice represents the idea that it is the individual's choice whether or not to have cosmetic surgery. Ten respondents expressed statements such as "I think that if people want to do that kind of thing they can," "I understand why some people may want to and support them if they believe it would make them more comfortable ... it is their choice after all," and "It's a personal choice." Although these respondents stated their support for cosmetic surgery, this can also be viewed as an unwillingness to judge others or at least to be seen to judge others. This may reflect a true desire to support the personal choice of others or may be designed to save face or otherwise protect one's own integrity.

Finally, a total of seven respondents stated financial reasons, such as "I think that cosmetic surgery is too costly, so I wouldn't be able to get it. But if I was, I would get the fat pumped out of my stomach, so I'd look like I had abs" and "I am in favour of cosmetic surgery. If I could afford it, I would not think twice about having such surgeries within moderation." Interestingly, this is the first theme where participants are using "I" versus "they" when discussing cosmetic procedures. Here, the men are saying that they personally support or would undergo procedures if they could afford to do so. Perhaps because these participants have made it clear that the financial cost is prohibitive - so they cannot possibly partake of cosmetic surgery - they are able to admit that they have considered it. In other words, the financial barriers work as social distancing and it is not necessary for these participants to use a hypothetical "they" or "other men."

These supportive themes are reflective of the role of habitus in shaping how individuals perceive themselves and their surroundings. The social conditioning from which habitus originates teaches individuals to value their appearance and the importance of attractiveness in daily living. Cultural and social exposure shapes the habitus, as well as how individuals construct their social reality (Bourdieu, 1984). Our findings regarding self-esteem and social distance suggest that Canadian men's 
perspectives on cosmetic surgery have been shaped by cultural and societal exposures that have taught men the importance of appearance and the body but the inappropriateness of cosmetic surgery for men.

\section{Unsupportive of cosmetic surgery}

Most participants against cosmetic surgery stated reasons related to the importance of being happy with and accepting one's "natural" body. This category was composed of thirteen responses. Respondents here advocated that people should appreciate what they already have. For example, respondents stated that "we were born the way we're meant to be and we should accept ourselves and others the way we are," "natural is beautiful, honestly" and "people should be happy with who they are and what they look like." Considering the wealth of literature on body modification (e.g., Featherstone 1991; Giddens 1991; Gill et al., 2005; Pope et al. 2000), it may at first appear strange that these men are claiming that the body should be left alone and appreciated as is. Of course, it is possible that these men are reacting to the perceived unnatural aspect of cosmetic surgery itself (whether because it is surgical or traditionally feminine) rather than body modification per se. In other words, it would be interesting to investigate whether these men were similarly unsupportive of weight lifting, sports, or body piercing.

The cost of cosmetic surgery emerged among respondents who did not support it as well. Approximately eight participants mentioned this theme, reporting things such as "I think it is too dangerous and it costs a lot" and "I feel it is a complete waste of time and money." As among respondents who were supportive of cosmetic surgery but mentioned finances, those who were unsupportive of cosmetic surgery for this same reason also expressed themselves with the first person pronoun "I." Six respondents stated moral condemnation or religiosity as reasons for their opposition. Respondents felt that their bodies were created by God, necessitating respect, and that failure to do so was an act of immorality. Participants said things such as "I feel that you are blessed by God to even have an able body" and "our bodies are not our property but that of God. I feel whatever God has provided me with is plenty and I am very thankful for how He has created me" and "[cosmetic surgery is] for the devil." These participants justified their perspective on cosmetic surgery by appealing to external authoritative sources, which were situated in religion. Not only are they themselves deploring cosmetic surgery, but their cultural exposures dictate that it is morally wrong.

The final themes were vanity and laziness. Elements of many responses could be categorized as vain, such as "[it's for people who are] vain and I make negative judgments about people who undergo proced- 
ures" and "it is for shallow people." Responses categorized as laziness tended to suggest that cosmetic surgery was a replacement for diet and exercise for people that lacked drive, motivation, and discipline. Examples include: "I think cosmetic surgery is a lazy way out. If you want to improve your appearance you need to have the motivation to do it yourself the natural way" and "I believe that if you aren't happy with what you've got, change your appearance naturally, by making the time, and committing yourself to working out, or exercising, or eating better. I know from personal experience that it can be hard." Again, elements of what is and what is not "natural" have surfaced. Future research may wish to explore whether cosmetic surgery is unnatural because it is a surgery or because it is not traditionally masculine. In addition, as vanity and slothfulness are two of Christianity's mortal sins, it is perhaps not surprising that participants' responses in these themes were also at times couched within religion.

Respondents who did not support cosmetic surgery tended to be less open to contemporary views of masculinity, instead valuing notions of hegemonic masculinity where men must be strong, disciplined, and "natural" (Connell 1987). It appears that factors within these men's habitus place importance on being "manly" and these men feel that having cosmetic surgery violates traditional notions of masculinity. For example, normative masculinity dictates that men should not be concerned about their appearance; men should not admit to suffering from something they are not supposed to care about in the first place (Davis 2002; Pope et al. 2000). The cultural and social exposures of these men dictate that appearance concerns are trivial and men should be happy with their natural body. Thus, only physical change via intense physical work and will power is acceptable. These findings reflect Davis's (2002:60) explanation that "the male cosmetic surgery recipient crosses the border of what is considered acceptable masculine demeanour. He acts like a woman." For these Canadian men, such a possibility is unacceptable and, for many, against the will of God.

\section{General Discussion}

Bourdieu (1984) explains that the struggle for social distinction is an underlying aspect of all social life. In the realm of aesthetics, he argues that social class determines one's likes and dislikes and such class distinctions are reinforced in daily living. In terms of aesthetics, he explains,

it must never be forgotten that the working-class 'aesthetic' is a dominated 'aesthetic' which is constantly obliged to define itself in terms of 
the dominant aesthetics.... Similarly, in contemporary society, it is one's social position and cultural exposure that determines not only one's likes and dislikes but also what one deems attractive and acceptable. (1984:41)

Our findings suggest that social distinction, in terms of physical attractiveness, self-perceptions, and the perceptions of others, remains evident among Canadian men.

Theorists have long argued that how we are seen, or believe we are seen, in the eyes of others dramatically affects our sense of self (Cooley 1933; Mead 1934). Our findings support such theoretical conceptions, as men with lower self-confidence were more likely than men with higher self-confidence to feel that others considered them lazy because of their appearance. Furthermore, men lower in self-esteem believed that their appearance decreased their self-confidence. This negative trend may be related to the hypervisibility of men in the media. Men are increasingly depicted and praised in the media for their appearance (Featherstone 1991; Gill et al. 2005; Simpson 1994); this constant bombardment with images of unachievable yet idealized masculine embodiment may lead men to feel their own physical appearance is insufficient. Peter West (2000:5) suggests that "giving untoward praise to one man's appearance lords him over all the rest of us, encouraging feelings of inferiority and poor self-esteem." Thus, not only can the increased visibility of the male body impact how a man feels about himself, but it may also affect how he feels he is perceived by others.

We found that men higher in self-deprecation were more likely to be uncomfortable with their bodies, be embarrassed by their bodies, and to dislike their bodies than men lower in self-deprecation. Thus, selfdeprecation appears to be reflective of body image. In light of the role of the body in identity construction, dissatisfaction with one's body image combined with high self-deprecation may lead to negative self-images among men. Importantly here, self-confidence was not significant in relation to body shape, but was a significant predictor of weight issues and willingness to undergo cosmetic surgery, whereas self-deprecation was not. This further demonstrates that self-esteem is composed of two related but distinct factors - self-confidence and self-deprecation and that these two concepts affect body image in unique ways. Future research on the body may refine the differentiation between these two dimensions of self worth.

In regard to body modification, we found that men felt cosmetic surgery may improve their appearance and thus make it easier to meet women or to feel more confident in different social situations. For example, one respondent stated: 
I know people should be happy with who they are and what they look like, but if someone sees himself as unattractive, cosmetic surgery may be a way that they can try and make themselves feel good. I think it may be easier for some people to find someone if they had cosmetic surgery just to increase their confidence and maybe their dating appeal.

Both our quantitative and qualitative findings suggest that men with lower self-confidence have more positive attitudes toward cosmetic surgery and are more willing to consider undergoing such procedures.

Because cosmetic surgery has been traditionally associated with women, it appears that Canadian men - even men who are supportive - have some difficulties incorporating cosmetic surgery into their repertoire of acceptable male body modification practices. Men who were supportive of cosmetic surgery tended to talk about it in terms of hypothetical others. These men claimed that cosmetic surgery was acceptable for a variety of reasons, but often spoke of it in the third person unless it was clear that they themselves could not partake of it (e.g., too expensive). Men who were not supportive of cosmetic surgery often appealed to higher authorities to justify their disapproval. For example, participants often said it was unnatural or against the will of God. For many of these men, their own personal view was somehow insufficient. According to Bourdieu (1990), people do not choose how to present the self; instead, people appraise any given social situation based on their past cultural and social exposures and then act appropriately. Based on the responses of our participants, it is clear that cosmetic surgery has not yet been incorporated into the habitus of Canadian men.

Our findings suggest that cosmetic surgery may be used to "fix" social issues as much as perceived physical "imperfections." This is supported by the opinion of many participants that confidence may improve with cosmetic surgery. This inaccurate belief that cosmetic surgery can cure psychological issues has been referred to in the media as "Prozac with a knife" (Esptein 2000). Thus, when evaluating potential patients, cosmetic surgeons agree that some must be denied the treatments they request because they will never be satisfied with the outcome (Davidson 2004). Men may have multiple surgical procedures because of their perceived "need" for further "correction" and the emergence of new "problem areas" after each old area is "treated" (Hayt 2002). This also brings to light the reality of body dysmorphic disorder (BDD). Pope et al. (2000) believe that BDD will become even more common as men continue to face more unrealistic pressures to look a certain way. Thus, cosmetic surgery as a manner to improve one's appearance has a secondary function of active identity construction. 
Being held responsible for the shape and design of their own bodies can present difficult situations for men, because their body is also a source of self-identification. For example, as our findings suggest, men may experience less self-confidence, more self-deprecation, or more discomfort with their bodies if they do not feel they are "physically attractive" according to social standards of attractiveness. Although men have traditionally been able to work on their bodies through weight lifting, tattooing and piercing, sports and exercise (Gill et al. 2005; Pope, et al. 2000; West 2000), other research suggests that men are also venturing into body modification practices that are more stereotypically feminine, such as grooming and cosmetic surgery (e.g., Davis 2002). We provide evidence that while men may now be more likely to consider or partake in cosmetic surgery, they still feel ambivalent toward these more traditionally feminine options. In addition, Bordo (1993) explains that the ability to manipulate physical appearance also leads individuals to feel increasingly detached from the body. These feelings of detachment may lead to a fragmentation of the body, where different features or body parts may be seen as separate from the ideal whole. The consequences of this detachment and fragmentation, combined with the increased visibility of the male body in the media, can be far reaching (e.g., BDD). In particular, these processes have a dramatic affect on one's identity and sense of self.

\section{Future Research}

The current research, involving a sample of men from the Greater Toronto Area, was conducted using an online survey, encompassing all the strengths (e.g., greater anonymity) and weaknesses (e.g., greater possibility for distracters) that these surveys entail. Future research using other samples and methods would help to test the generalizability of these findings. An exploration into cultural differences also seems warranted by future research. As stated earlier, Bordo (1993:16) sees that "culture's grip on the body is a constant, intimate fact of everyday life." Individuals from different religions, ethnicities, nationalities, and sexualities possess different cultures. For example, some cultures promote the hiding of the body through particular traditions in dressing, while others use clothing to reveal the body. How these differing cultures specifically influence the body in regards to self-esteem (self-confidence versus self-deprecation) and comfort with the body is an area for future research to pursue. Regarding cosmetic surgery in particular, future research may wish to further explore how men use social distancing to talk about traditionally feminine forms of body modification, such as 
cosmetic surgery. Interviews may provide an ideal method to flesh out and pursue Canadian men's affect and reasoning surrounding cosmetic surgery.

\section{Conclusion}

Normative masculinity dictates that men should not be concerned about their physical appearance (Connell 1995), but men are bombarded with images of an unachievable physical ideal. This increasing hypervisibility of the male body may hinder the development of self-esteem, leading to lower self-confidence, greater self-deprecation, and lower levels of comfort with the body. Simply having these concerns, which have traditionally been associated with femininity (Davis 2002), violates normative masculinity and may further compromise men's self-esteem. It is important to remember that the body does not exist in isolation. It is through our interactions that we develop an understanding of how we are perceived by others (Cooley 1933; Mead 1934). These interactions may lead us to make positive or negative associations with our body. Moreover, these interactions may influence how we perceive our body, thus influencing our levels of body comfort and self-esteem. Thus, the hypervisibility of the male body and normative masculinity, as well as other variables such as personal history, family upbringing, and culture, negatively affect men's self-esteem.

Literature on the body explains that when men contemplate body modification, they are actively engaging in identity construction (Gill et al. 2005). In this regard, the physical body is increasingly linked to how individuals self-identify. However, by working on the body - with fashion, grooming, and cosmetic surgery - men are falling prey to consumer culture (Featherstone 1991; Shilling 2003). Men may have a false sense of empowerment and control over their body because it appears to be a tangible area that can be regulated, dominated, and manipulated via aesthetics, surgery, diet, and exercise. In reality, the biological composition of the body cannot be fully controlled or manipulated because it is embedded in physical limitations that influence one's appearance. For example, men can only gain so much muscle or lose so much weight naturally. As more men try to control their bodies in unrealistic ways, we will likely see an increase in related psychological issues (such as BDD) among men. Overall, as men continue to base their notions of attractiveness on the social reality learned within their habitus, they will often find that their ideal body is unachievable and serves as a source of dissatisfaction with the self. 


\section{REFERENCES}

Alba, Joseph W. 2000. Dimensions of consumer expertise ... or lack thereof. Advances in Consumer Research 27:1-9.

American Society of Plastic Surgeons. 2007.2006 Quick Gender Facts Cosmetic Plastic Surgery. Department of Public Relations, Arlington Heights, IL. Retrieved April 11, 2008 at www.plasticsurgery.org

Archer, D., B. Iritani, D. Kimes, and M. Barrios. 1983. Face-ism: Five studies of sex differences in facial prominence. Journal of Personality and Social Psychology 45:725-735.

Averett, Susan and Sanders Korenman. 1996. The economic reality of the beauty myth. The Journal of Human Resources 31(2):304-330.

Bargh, John A. 2002. Losing consciousness: Automatic influences on consumer judgment, behavior and motivation. The Journal of Consumer Research 29(2):280-285.

Bartky, Sandra L. 1990. Femininity and Domination: Studies in the Phenomenology of Oppression. New York: Routledge.

Baurneister, Roy F. 2002. Yielding to temptation: Self-control failure, impulsive purchasing, and consumer behavior. Journal of Consumer Research 28(March):670-676.

Bordo, Susan. 1993. Unbearable Weight. Berkeley, CA: University of California Press.

1999. The Male Body: A New Look at Men in Public and Private. London: Farrar, Straus and Giroux.

Bourdieu, Pierre. 1978. Sport and social class. Social Science Information 17(6):819-840. 1984. Distinction: A Social Critique of the Judgment of Taste. London: Routledge.

1987. The historical genesis of a pure aesthetic. The Journal of Aesthetics and Art Criticism 46(Analytic Aesthetics):201-210. 1990. In Other Words: Essays Towards a Reflexive Sociology, trans. M. Adamson. Stanford, CA: Stanford University Press.

Bourdieu, Pierre and Terry Eagleton. 1992. Doxa and common life. New Left Review 191:111-121.

Bryant, Rebecca. 2003. Spotting body dysomorphic disorder, hidden problems. Cosmetic Surgery Times October: 6.

Budgeon, Shelley. 2003. Identity as an embodied event. Body and Society 9(1):35-55.

Carrigan, T., R.W. Connell, and J. Lee. 1985. Towards a new sociology of masculinity. Theory and Society 14(5):551-604.

Chapman, R. and J. Rutherford. 1988. Male Order: Unwrapping Masculinity. London: Lawrence and Wishart. 
Cohen, Joel B. and Dipankar Chakravarti. 1990. Consumer psychology. Annual Review of Psychology 41:243-288.

Connell, R.W. 1983. Which Way Is Up? London/Boston: Allen \& Unwin. 1987. Gender and Power. Cambridge: Polity Press. 1995. Masculinities. Cambridge: Polity Press.

Cooley, Charles Horton. 1933. Introductory Sociology. New York: C. Scribner's Sons Inc.

Courtney, A. and T. Whipple. 1983. Sex Stereotyping in Advertising. Lexington, MA: Lexington Books.

Davidson, Hilary. 2004. Flawless! Chatelaine 77(2, February):115.

Davis, Kathy. 1997. Embodied Practices. Thousand Oaks, CA: Sage. 2002. 'A dubious equality': Men, women and cosmetic surgery. Body and Society 8(1):49-65.

Edwards, T. 1997. Men in the Mirror: Men's Fashion, Masculinity and Consumer Society. London: Cassell.

Ehrenreich, Barbara and Deirdre English. 1978. For her own Good: 150 Years of the Experts' Advice to Women. New York: Doubleday Inc.

Epstein, Joseph. 2000. Prozac, with knife. Commentary, 110 July/August (1):5458.

Featherstone, Michael. 1991. The body in consumer culture. Pp. 170-196 in M. Featherstone, M. Hepworth, and B. Turner, eds., The Body: Social Process and Cultural Theory. London: Sage.

Giddens, Antony. 1991. Modernity and Self-Identity: Self and Society in the Late Modern Age. Cambridge: Polity Press.

Gill, Rosalind, Karen Henwood, and Carl McLean. 2000. The tyranny of the six-pack: Men talk about idealized images of the male body in popular culture. In C. Squire, ed. Culture in Psychology. London: Routledge. 2005 . Body projects and the regulation of normative masculinity. Body \& Society 11(1):37-62.

Goffman, Erving. 1968. The Presentation of Self in Everyday Life. New York: Penguin.

1979. Gender Advertisements. Cambridge, MA: Harvard University Press.

Grogran, S. 1999. Body Image: Understanding Body Dissatisfaction in Men, Women and Children. London: Routledge.

Gullette, Margaret Morganroth. 1994. All together now: The new sexual politics of midlife bodies. Pp. 22-47 in L. Goldstein, ed., The Male Body. Ann Arbor, MI: Michigan University Press.

Hall, Christine C. and M.J. Crum. 1994. Women and "body-isms" in television beer commercials. Sex Roles: A Journal of Research 31(5-6):329-337. 
Haworth-Hoeppner, Susan. 2000. The critical shapes of body image: The role of culture and family in the production of eating disorders. Journal of Marriage and the Family 62(1):212-227.

Hayes, Diane and Catherine E. Ross. 1986. Body and mind: The effect of exercise, overweight, and physical health on psychological well-being. Journal of Health and Social Behavior 27(December):387-400.

Hayt, Elizabeth. 2002. Addicted to plastic surgery. Harper's Bazaar 135(3483, February):76.

Hesse-Biber, Sharlene. 1996. Am I Thin Enough Yet? The Cult of Thinness and the Commercialization of Identity. New York: Oxford University Press.

Hoelter, Jon W. 1984. Relative effects of significant others on self-evaluation. Social Psychology Quarterly 47(3):255-262.

Jacoby, Jack, Gita Johar, and Maureen Morrin. 1999. Consumer behavior: A quadrennium. Annual Review of Psychology 49:319-344.

Lerner, Richard M. 1969. Some female stereo-types of male body build-behavior relations. Perceptual and Motor Skills 28:363-366.

Lerner, Richard M. and Sam J. Korn. 1972. The development of body-build stereo-types in males. Child Development 43:248-260.

Lueptow, L., L. Garovich-Szabo, and M. Lueptow. 2001. Social change and the persistence of sex typing: 1974-1997. Social Forces 80:1-36.

Mead, George Herbert. 1934. Mind, Self and Society from the Standpoint of a Social Behaviorist: The Works of George Herbert Mead. Chicago: University of Chicago Press.

Moore, S. 1988. 'Here's Looking at You Kid!' The Female Gaze - Women as Viewers of Popular Culture. London: The Women's Press.

Mort, F. 1996. Cultures of Consumption: Masculinities and Social Space in Late 20th Century Britain. London: Routledge.

Nixon, S. 1996. Hard Looks: Masculinities, Spectatorship and Contemporary Consumption. London: University College London.

Owens, Timothy J. 1993. Accentuate the positive - and the negative: Rethinking the use of self-esteem, self-depreciation, and self-confidence. Social Psychology Quarterly 56(4):288-299.

Pope, H., K. Phillips, and R. Olivardia. 2000. The Adonis Complex: How to Identify, Treat and Prevent Body Obsession in Men and Boys. New York: Simon and Schuster.

Rosenberg, Morris. 1979. Conceiving the Self. New York: Basic Books.

Rosenberg, Morris, Carmi Schooler, and Carrie Schoenbach. 1989. Self-esteem and adolescent problems: Modelling reciprocal effects. American Sociological Review 54(6):1004-1018. 
Rosenberg, Morris, Carmi Schooler, Carrie Schoenbach, and Florence Rosenberg. 1995. Global self-esteem and specific self-esteem: Different concepts, different outcomes. American Sociological Review 60(1):141-156.

Ross, Catherine E. 1994. Overweight and depression. Journal of Health and Social Behavior 35(March):63-78.

Rowan, David. 2004. Rise of the new neurotics. The Times (London), Saturday June 19.

Shilling, Chris. 2003. The Body and Social Theory (2nd. ed.). London: Sage.

Simpson, Michael. 1994. Male Impersonators: Men Performing Masculinity. London: Cassell.

Sullivan, G. and P.J. O'Connor. 1988. Women's role portrayals in magazine advertising: 1958-1983. Sex Roles 18:181-188.

Sullivan, Deborah A. 2001. Cosmetic Surgery: The Cutting Edge of Commercial Medicine in America. New Brunswick, NJ: Rutgers University Press.

Trujillo, N. 2000. Hegemonic masculinity on the mound: Media representations of Nolan Ryan and American sports culture. Pp 14-19 in S. Birrell and M. McDonald, eds., Reading Sport: Critical Essays on Power and Representation. Boston: Northern University Press.

Wiederman, Michael W. and Shannon R. Hurst. 1998. Body size, physical attractiveness, and body image among young adult women: Relationships to sexual experience and sexual esteem. The Journal of Sex Research 35(3):272-282.

West, Peter. 2000. From Tarzan to the Terminator: Boys, men and body image. Institute of Family Studies Conference, Sydney, 24, July 2000. Work in progress paper.

Wolf, Naomi. 1991. The Beauty Myth. London: Chatto and Windus.

Rosemary Ricciardelli is a $\mathrm{PhD}$ candidate in Sociology at McMaster University. Her dissertation centers on evolving masculinity, male corporeality and self-identification. Primarily, her research focuses on negotiating masculinity in contemporary society and how men embody masculinity. Her other interests include discrimination, sexuality and deviance more generally, and gender in particular. Current projects include investigating men's perspectives on masculinity, physical appearance and body modification, specifically cosmetic surgery, as well as the stereotypes and prejudice surrounding men in nursing.

Kimberley A. Clow is an Assistant Professor in the Faculty of Criminology, Justice and Policy Studies at the University of Ontario Institute of Technology. She received her $\mathrm{PhD}$ in Psychology from the University of Western Ontario. Her primary research interests focus on stereotypes, prejudice, and discrimination as well as gender. Her current projects in this area include examining stereotypes and prejudice regarding men in nursing and men's perspectives on appearance and masculinity. 